\title{
Support for tobacco control initiatives among physicians and dentists who treat adolescent patients
}

\author{
David I Gregorio
}

\begin{abstract}
Objective - To survey physicians and dentists who treat adolescent patients about their support for and involvement in community public health initiatives to reduce tobacco use among minors.

Design-Pediatricians, family practitioners and dentists across Connecticut were asked their views about eight policy options to control tobacco.

Subjects-Questionnaires were distributed to 674 practitioners; 443 responses $(66 \%)$ were analysed.

Major outcome measures - Personal attributes of respondents, characteristics of their practices, their support for eight tobacco control policies, and their personal involvement in community control activities.
\end{abstract}

Results-Respondents favoured measures to control access of adolescents to tobacco. Mandatory tobacco prevention curricula in schools, higher tax on tobacco sales, and prohibiting tobacco advertising in public places were supported by more than $75 \%$ of respondents. Significant support was expressed for prohibiting tobacco sales through vending machines (68\%), fining merchants who sell tobacco to minors (67\%), limiting point of sale for tobacco $(63 \%)$, and earmarking tobacco tax revenues to support prevention programmes $(58 \%)$. Physicians were more likely than dentists to express support for these initiatives. Practitioners who routinely counsel adolescents about smoking were more likely to express definite support for tobacco control measures compared with those who counsel young patients infrequently. Personal involvement by these practitioners in community activities to control tobacco was negligible.

Conclusion - Physicians and dentists can be invaluable constituents in our effort to control access of adolescents to tobacco products. These findings reveal areas where further professional education and involvement in community tobacco control activities may be beneficial.

(Tobacco Control 1994; 3: 208-212)

Introduction

Intense warnings over the past 30 years about the hazards of tobacco have diminished but not curtailed its use. One in six of our nation's children risk becoming regular smokers, and one-quarter of them, or five million individuals, will die unnecessarily from their addiction. ${ }^{1}$ Recent surveys relying upon selfreported prevalence of smoking among adolescents reveal that two-thirds of 9th graders have previously tried cigarettes and that $8-16 \%$ of persons in grades $9-12$ are termed frequent users (ie, usage on at least 20 of the 30 days preceding the survey). ${ }^{2}$

Clearly, smoking is not a matter of free choice. The insidious effects of marketing tobacco to young, vulnerable consumers are

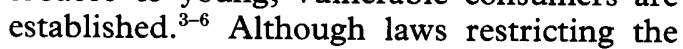
sale of tobacco to minors were in place in 46 states and the District of Columbia, ${ }^{7}$ illegal sale of cigarettes to minors was estimated to exceed 255 million packs in $1991 .^{8}$ Such ready availability of cigarettes ${ }^{9,10}$ helps produce 3000 young smokers every day. By the time those smokers recognise the harmful effects of their behaviour, most will have difficulty quitting.

Physicians and dentists have significant clinical responsibilities helping young adults avoid tobacco. ${ }^{11,12}$ They have frequent contact with these patients and often serve as powerful role models for appropriate health practices. ${ }^{13}$ The American Medical Association's Guidelines for Adolescent Preventive Services (GAPS) recommend annual health guidance of persons between the ages of 11 and 21 about avoiding tobacco and other abusable substances and screening such patients each year about cigarette use. ${ }^{14}$

Health care providers have equally important, albeit less well-defined, roles in shaping opinion and advancing public policy to establish a tobacco-free environment. Healthy People 2000 objectives call for communities to establish comprehensive tobacco control plans, provide curricula for tobacco use prevention in all elementary and secondary schools, curtail tobacco product advertising to which adolescents may be exposed, and enact laws prohibiting sale and distribution of tobacco to persons younger than age $19 .{ }^{1}$ Their knowledge and experience, along with pledges of objectivity and altruism, ${ }^{15}$ make physicians and dentists credible advocates for control measures.

This study surveyed physicians and dentists who treat adolescent patients about their support for and involvement in community public health initiatives to reduce tobacco use 
among minors. The analysis increases our understanding of the role these practitioners can and do play in the social control of cigarette

$*<$ use.

$=$

$x$

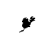

$-\infty$

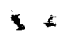

5

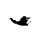

$-1$

f.

2.

$+$

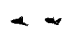

3

$y=$

2

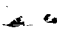

$-4$

$\div$

$=$

$x=$

$\therefore$

-

$*$

$+$

$c-$

a.

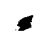

- 4

32

$=$
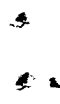

\section{Methods}

During Spring 1992, samples of pediatricians $(n=156)$, family practitioners $(n=261)$ and dentists $(n=257)$ from across Connecticut were sent a brief questionnaire to gauge their support for eight specific options to control access of minors to tobacco and to measure their personal involvement in tobacco control efforts. Roughly a third of pediatricians and general dentists at practice in the State and two-thirds of family physicians were contacted using membership rosters provided by the respective state associations.

The initial mailing yielded $354(52 \%)$ responses. A follow-up request to 320 nonrespondents produced an additional 89 replies. Usable information was obtained from 443 individuals; $105(65 \%)$ pediatricians, 172 $(66 \%)$ family practitioners, and $166(65 \%)$ dentists. Initial and follow-up respondents, as well as their responses, were similar and were combined for the analysis. Unfortunately, it was not possible to compare survey responders with non-responders or non-members of professional organisations.

The questionnaire measured personal attributes of respondents and characteristics of their practices, their smoking histories, their perceptions of how regularly they counsel adolescents about tobacco (ie, always, frequently, occasionally, never), and their intention to support specific policies to control access of minors to tobacco. Eight options proposed or in place around the country ${ }^{16}$ were examined: a) require tobacco use prevention curricula in schools, $b$ ) require tobacco sales tax to be allocated for tobacco use prevention programmes, $c$ ) increase tax on sale of tobacco products, $d$ ) ban advertising of cigarettes from public areas, $e$ ) prohibit tobacco companies from sponsoring sports or cultural events, $f$ ) limit points of sale of all tobacco products in a similar way to that done for alcohol, $g$ ) prohibit sale of tobacco products through vending machines, and $h$ ) impose fines on merchants who sell tobacco to minors. For every option, respondents could reply that they would definitely support, would probably support, or would not support such an initiative for their community.

Respondents also were asked whether they had undertaken personal initiatives within the previous 12 months to support community public health efforts to control tobacco. Specific probes concerned such activities as: $a$ ) making monetary contributions to smoking prevention programmes, $b$ ) avoiding purchase of products or investments related to tobacco companies, $c$ ) obtaining information or attending programmes on how to counsel patients to avoid tobacco use, $d$ ) addressing school children on tobacco and health, $e$ ) contacting legislators and other public officials to express support for tobacco control efforts, $f$ ) writing commentaries in local newspapers about tobacco use, and $g$ ) signing petitions on tobacco control.

Calculation of descriptive and inferential statistics was accomplished using established statistical software. ${ }^{17}$

\section{Results}

As a group, respondents were predominately male $(86 \%)$; most reported never smoking $(64 \%)$ and the median years in practice was 14 years. Forty-two per cent of respondents worked in solo practices, an additional $44 \%$ worked in private group practices, and the remainder $(14 \%)$ worked in other settings (eg, hospital clinics, health maintenance organisations, etc). Among those reported to be in private practices, dentists were more likely than physicians to be solo practitioners $(62 \%$ vs $38 \%$ ) and to have more years in practice (18.8 vs 15.9 years).

Generally, survey respondents favoured proposed measures to control access of adolescents to tobacco (see table 1). Three of every four individuals expressed definite support for mandatory tobacco prevention curricula in schools $(77 \%)$, higher tax on tobacco sales $(77 \%)$, and prohibiting tobacco advertising in public places $(76 \%)$. Somewhat fewer, although still significant majorities of respondents, supported prohibiting tobacco sales through vending machines $(68 \%)$, fining merchants who sell tobacco to minors $(67 \%)$, limiting point of sale for tobacco $(62 \%)$, and earmarking tobacco tax revenues to support prevention programmes $(58 \%)$. Only one control option, prohibiting tobacco companies from sponsoring cultural or athletic events, failed to gain support from a majority of respondents $(48 \%)$. For seven of the eight options considered, only about one in 10 respondents indicated an intention not to support particular control options. The exception, prohibiting tobacco companies from sponsoring sports or cultural events, was opposed by one in four respondents.

Physicians, as a rule, were less equivocal than dentists in expressing their support for the various control initiatives. Six of eight comparisons between specialists revealed significant differences in attitude. For example, approximately two-thirds of pediatricians and family practitioners indicated they would definitely support a policy requiring tobacco tax revenues to be allocated for prevention programmes, while only $47 \%$ of dentists responded in that way. More than $80 \%$ of physicians indicated that they definitely supported efforts to ban tobacco advertising from public places, whereas only $65 \%$ of dentists intended to support such a measure. Similarly, substantially more physicians than dentists endorsed policies intended to reduce cigarette availability by limiting points of sale in a similar way to that done for alcoholic beverages $69 \%$ vs $52 \%$, respectively) or prohibit distribution of tobacco through vending machines ( $75 \%$ vs $57 \%$, respectively). A majority of physicians $(57 \%)$ indicated they would sup- 
Table 1 Percentage of respondents expressing intent to support tobacco control policies by selected characteristics of respondents

\begin{tabular}{|c|c|c|c|c|c|c|c|c|c|}
\hline \multirow[b]{2}{*}{ Proposed control measure } & \multirow[b]{2}{*}{$\begin{array}{c}\text { Total } \\
(n=443)\end{array}$} & \multicolumn{2}{|c|}{ Specialty } & \multicolumn{2}{|c|}{$\begin{array}{c}\text { Practice } \\
\text { arrangement }\end{array}$} & \multicolumn{2}{|c|}{$\begin{array}{l}\text { Years in } \\
\text { practice }\end{array}$} & \multicolumn{2}{|c|}{ Smoking history } \\
\hline & & $\begin{array}{c}\text { Dentist } \\
(n=167)\end{array}$ & $\begin{array}{l}\text { Physician } \\
(n=276)(n\end{array}$ & $\begin{array}{c}\text { Solo } \\
n=186)\end{array}$ & $\begin{array}{c}\text { Group } \\
(n=195)\end{array}$ & $\begin{array}{c}1-14 \\
(n=215)\end{array}$ & $\begin{array}{l}\geqslant 15 \\
n=198)\end{array}$ & $\begin{array}{c}\text { Ever } \\
(n=160)\end{array}$ & $\begin{array}{c}\text { Never } \\
(n=268)\end{array}$ \\
\hline \multicolumn{10}{|l|}{ Iïigher sales tax } \\
\hline Definitely would support & 77 & 72 & 80 & 71 & 80 & 81 & 72 & 72 & 79 \\
\hline Probably would support & 16 & 20 & 14 & 18 & 15 & 14 & 19 & 18 & 15 \\
\hline Would not support & 7 & 8 & 6 & 11 & 4 & 5 & 10 & 10 & 5 \\
\hline \multirow{5}{*}{$\begin{array}{l}\text { Allocate tax for prevention } \\
\text { Definitely would support } \\
\text { Possibly would support } \\
\text { Would not support }\end{array}$} & \multicolumn{7}{|c|}{$\left(\chi^{2}=3.6 ;\right.$ n.s. $) \dagger\left(\chi^{2}=6.8 ; \mathrm{p}=0.03\right)\left(\chi^{2}=5.9 ; \mathrm{p}=0.05\right)$} & \multicolumn{2}{|c|}{$\left(\chi^{2}=4.1 ;\right.$ n.s. $)$} \\
\hline & 58 & 47 & 65 & 53 & 61 & 60 & 56 & 51 & 62 \\
\hline & 32 & 40 & 27 & 35 & 30 & 30 & 33 & 37 & 29 \\
\hline & 10 & & 8 & 12 & 9 & 10 & 10 & 11 & 9 \\
\hline & & \multicolumn{2}{|c|}{$\left(\chi^{2}=12.0 ; p<0.01\right)$} & \multicolumn{2}{|c|}{$\left(\chi^{2}=2.8 ;\right.$ n.s. $)$} & \multicolumn{2}{|c|}{$\left(\chi^{2}=0.6 ;\right.$ n.s. $)$} & \multirow{2}{*}{\multicolumn{2}{|c|}{$\left(\chi^{2}=4.1 ;\right.$ n.s. $)$}} \\
\hline Definitely would support & 76 & 65 & 83 & 69 & 81 & 78 & 74 & & \\
\hline Possibly would support & 14 & 20 & 11 & 17 & 13 & 17 & 12 & $\begin{array}{l}73 \\
14\end{array}$ & $\begin{array}{l}78 \\
15\end{array}$ \\
\hline \multirow[t]{2}{*}{ Would not support } & 9 & & & & 6 & & 14 & & \\
\hline & & \multirow{2}{*}{\multicolumn{2}{|c|}{$\begin{array}{c}\left(\chi^{2}=18.3\right. \\
p<0.01)\end{array}$}} & \multirow{2}{*}{\multicolumn{2}{|c|}{$\begin{array}{c}\left(\chi^{2}=10.5\right. \\
\mathrm{p}<0.01)\end{array}$}} & \multirow{2}{*}{\multicolumn{2}{|c|}{$\begin{array}{c}\left(\chi^{2}=10.1\right. \\
p<0.01)\end{array}$}} & \multirow{2}{*}{\multicolumn{2}{|c|}{$\left(\chi^{2}=3.6 ;\right.$ n.s. $)$}} \\
\hline \multirow{5}{*}{$\begin{array}{l}\text { Limit point of sale } \\
\text { Definitely would support } \\
\text { Possibly would support } \\
\text { Would not support }\end{array}$} & & & & & & & & & \\
\hline & 62 & \multirow{5}{*}{\multicolumn{2}{|c|}{$\begin{array}{lr}52 & 69 \\
26 & 21 \\
21 & 10 \\
\left(\chi^{2}=14.2\right. \\
\mathrm{p}<0.01)\end{array}$}} & \multirow{5}{*}{\multicolumn{2}{|c|}{$\begin{array}{lr}53 & 69 \\
26 & 21 \\
20 & 10 \\
\left(\chi^{2}=11.6\right. \\
\mathrm{p}<0.01)\end{array}$}} & \multirow{5}{*}{\multicolumn{2}{|c|}{$\begin{array}{cc}66 & 59 \\
22 & 23 \\
12 & 18 \\
\left(\chi^{2}=3.9 ; \text { n.s. }\right)\end{array}$}} & \multirow{5}{*}{\multicolumn{2}{|c|}{$\begin{array}{lr}52 & 68 \\
27 & 21 \\
21 & 11 \\
\left(\chi^{2}=12.2\right. \\
\mathrm{p}<0.01)\end{array}$}} \\
\hline & 23 & & & & & & & & \\
\hline & 14 & & & & & & & & \\
\hline & & & & & & & & & \\
\hline \multicolumn{2}{|l|}{ Fine those who sell to minors } & & & & & & & & \\
\hline Definitely would support & 67 & & & 65 & 68 & 69 & 64 & & 72 \\
\hline Possibly would support & 20 & 23 & 18 & 20 & 20 & 22 & 17 & & 18 \\
\hline Would not support & 13 & 15 & 12 & 16 & 11 & & 18 & 20 & \\
\hline & & $\left(\chi^{2}=2\right.$ & (4; n.s.) & $\left(\chi^{2}=1\right.$. & 7 ; n.s.) & $\begin{array}{l}\left(\chi^{2}=\right. \\
p=0\end{array}$ & 3.8 & $\left(\chi^{2}=1\right)$ & 12.3 \\
\hline No vending machine sales & & & & & & & & & \\
\hline Definitely would support & 68 & 57 & 75 & 61 & 73 & 71 & 64 & & 75 \\
\hline Possibly would support & 20 & 26 & 16 & 23 & 18 & 18 & 22 & & 17 \\
\hline Would not support & 12 & 17 & & 16 & & 11 & 14 & 19 & \\
\hline & & $\begin{array}{l}\left(\chi^{2}=\right. \\
\mathrm{p}<\end{array}$ & $\begin{array}{l}15.4 \\
0.01)\end{array}$ & & & $\left(\chi^{2}=2.0\right.$ & ; n.s.) & & $\begin{array}{l}17.9 \\
0.01)\end{array}$ \\
\hline No sponsoring sport/cultural events & & & & & & & & & \\
\hline $\begin{array}{l}\text { Definitely would support } \\
\text { Possibly would support }\end{array}$ & $\begin{array}{l}48 \\
26\end{array}$ & & $\begin{array}{l}57 \\
23\end{array}$ & $\begin{array}{l}42 \\
27\end{array}$ & $\begin{array}{l}51 \\
26\end{array}$ & 46 & $\begin{array}{l}49 \\
22\end{array}$ & $\begin{array}{l}44 \\
26\end{array}$ & 50 \\
\hline Would not support & $\begin{array}{l}20 \\
26\end{array}$ & 36 & 20 & 31 & 22 & 24 & $\begin{array}{l}22 \\
29\end{array}$ & $\begin{array}{l}26 \\
30\end{array}$ & $\begin{array}{l}20 \\
24\end{array}$ \\
\hline Prevention curricula in schools & & $\left(\chi^{2}=23.3\right.$ & $; \mathrm{p}<0.01)$ & $\left(\chi^{2}=4\right.$ & ; n.s.) & $\left(\chi^{2}=3.8\right.$ & ; n.s.) & $\left(\chi^{2}=1.9\right.$ & ; n.s.) \\
\hline Definitely would support & 77 & 71 & 81 & 76 & & & & 74 & 79 \\
\hline Possibly would support & 18 & 21 & 16 & 18 & 17 & 20 & 14 & & 17 \\
\hline Would not support & 5 & 8 & 3 & 6 & 4 & 2 & 8 & 6 & 4 \\
\hline & & $\left(\chi^{2}=6.4\right.$ & $\mathrm{p}=0.04)$ & $\left(\chi^{2}=1\right.$ & n.s.) & $\left(\chi^{2}=3\right.$ & ; n.s.) & $\left(\chi^{2}=1.7\right.$ & 7; n.s.) \\
\hline
\end{tabular}

$\dagger \chi^{2}$ statistic indicates the relationship reported in $2 \times 3$ tables between predictor variables and expressed support.

port a measure to prohibit tobacco companies from sponsoring sports and cultural events, while only one-third of dentists indicated similar support.

Support for control initiatives also appeared to vary according to type of practice, years in practice, and history of tobacco use. Solo practitioners $(n=186)$, compared to those in group practices $(n=195)$, were less likely, in general, to indicate support for control measures. Group practitioners were more likely to express definite support for a higher sales tax on tobacco products $(80 \%$ vs $71 \%$, respectively), a ban of tobacco advertising in public places $(81 \%$ vs $69 \%)$, limits on the point of sale of tobacco products $(69 \%$ vs $53 \%)$, and prohibition of vending machine sales $(73 \%$ vs $61 \%$ ).

Respondents with 1-14 years in practice, as compared to those with over 15 years, were somewhat more likely to express support for control measures. Significant differences between groups were noted regarding measures to increase tobacco sales tax, ban public advertising of tobacco products, and fines for selling tobacco products to minors.

Respondents who reported never having smoked $(n=268)$ were consistently more likely to express support for control measures than practitioners who were either current or ex-smokers $(n=160)$. Never smokers were significantly more likely to support policies to limit the point of sale of tobacco $(68 \%$ vs $52 \%$ ), fine merchants who sell cigarettes to minors $(72 \%$ vs $57 \%$ ), and prohibit sale of tobacco through vending machines $(75 \%$ vs $56 \%$ ).

Because physicians and dentists in this study were found to differ according to practice arrangement and years in practice, the associations pertaining to specialty were re-examined when stratified by those control variables. As reported in table 2 , observed relationships between specialty and intention to support tobacco control measures were essentially unchanged when data were stratified by either practice arrangement or years in practice. Physicians, as compared to dentists, remained more likely to support proposed control measures regardless of whether they practiced in solo or group arrangements. Similarly, regardless of how long they were in practice, physicians tended to express greater support for control measures than dentists.

When the effects of practice arrangement and years in practice were re-examined controlling for the specialty of respondents, however, the bivariate associations noted in table 1 
Table 2 Percentage of respondents expressing intent to support tobacco control policies by specialty, practice arrangement, and years in practice

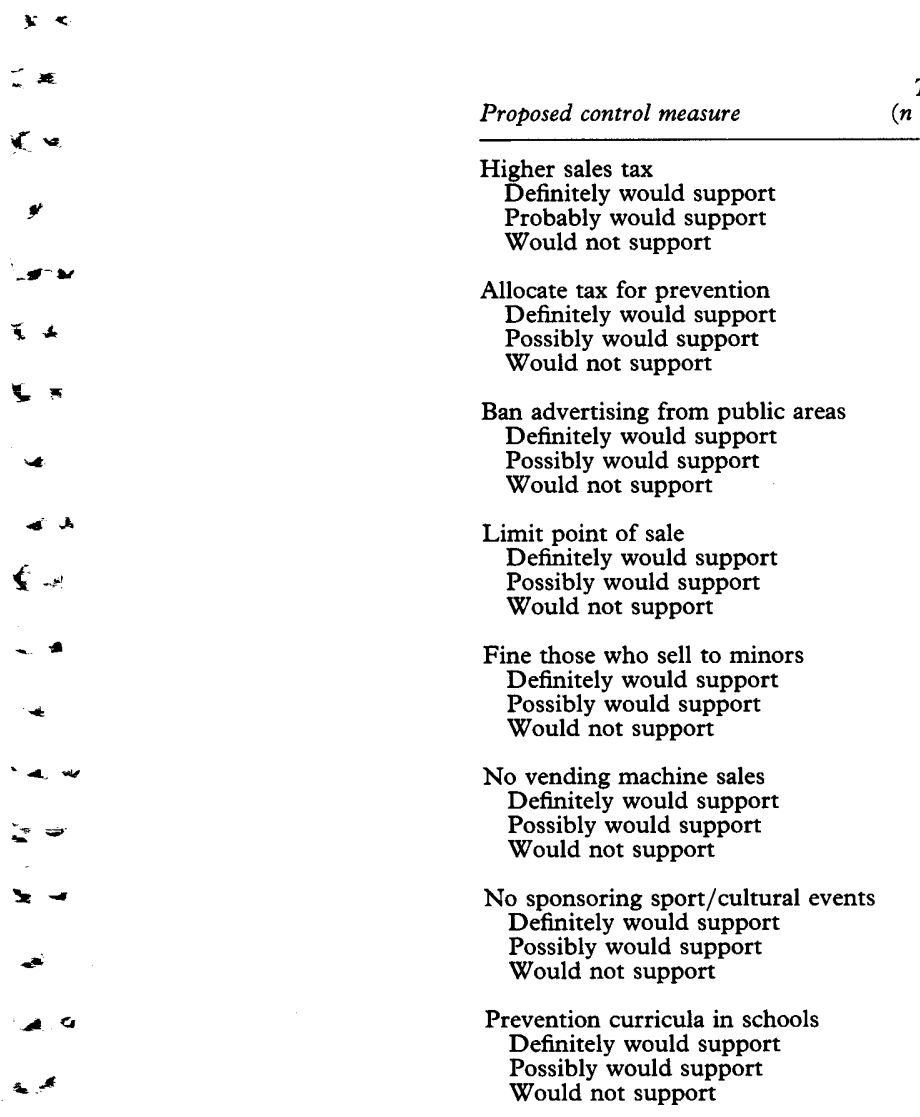

\begin{tabular}{|c|c|c|c|c|c|c|c|c|c|}
\hline \multirow[b]{3}{*}{ Proposed control measure } & \multirow[b]{3}{*}{$\begin{array}{c}\text { Total } \\
(n=443)\end{array}$} & \multicolumn{4}{|c|}{ Practice arrangement } & \multicolumn{4}{|c|}{ Years in practice } \\
\hline & & \multicolumn{2}{|c|}{ Solo practice } & \multicolumn{2}{|c|}{ Group practice } & \multicolumn{2}{|c|}{$1-14$} & \multicolumn{2}{|c|}{$>15$} \\
\hline & & $\begin{array}{c}\text { Dentist } \\
(n=95)\end{array}$ & $\begin{array}{c}\text { Physician } \\
(n=79)\end{array}$ & $\begin{array}{c}\text { Dentist } \\
(n=59)\end{array}$ & $\begin{array}{l}\text { Physician } \\
(n=186)\end{array}$ & $\begin{array}{c}\text { Dentist } \\
(n=66)\end{array}$ & $\begin{array}{l}\text { Physician } \\
(n=151)\end{array}$ & $\begin{array}{c}\text { Dentist } \\
(n=90)\end{array}$ & $\begin{array}{l}\text { Physician } \\
(n=110)\end{array}$ \\
\hline \multicolumn{10}{|l|}{ Higher sales tax } \\
\hline Definitely would support & 77 & 71 & 72 & 73 & 83 & 74 & 84 & 70 & 73 \\
\hline Probably would support & 16 & 18 & 14 & 24 & 12 & 22 & 11 & 19 & 18 \\
\hline Would not support & 7 & \multirow{2}{*}{\multicolumn{4}{|c|}{$\left(\chi^{2}=4.8 ;\right.$ n.s. $) \dagger$}} & \multirow{2}{*}{\multicolumn{4}{|c|}{$\left(\chi^{2}=4.3 ;\right.$ n.s. $)$}} \\
\hline Allocate tax for prevention & & & & & & & & & \\
\hline Definitely would support & 58 & 44 & 64 & 51 & 64 & 46 & 66 & 48 & 64 \\
\hline Possibly would support & 32 & 40 & 29 & 42 & 26 & 43 & 25 & 39 & 29 \\
\hline Would not support & 10 & 16 & $\left(\chi^{2}=13.4 ; \mathrm{p}<0.01\right)$ & $\begin{array}{c}7 \\
0<0.01)\end{array}$ & 9 & 11 & $\left(\gamma^{2}=135\right.$ & $p<0.01)$ & 7 \\
\hline \multicolumn{2}{|l|}{ Ban advertising from public areas } & & & & & & & & \\
\hline Definitely would support & 76 & 61 & 78 & 71 & 85 & 65 & 83 & 65 & 82 \\
\hline Possibly would support & 14 & 19 & 15 & 22 & 10 & 28 & 13 & 15 & 10 \\
\hline Would not support & 9 & 20 & & $p<\frac{7}{0.01\rangle}$ & 5 & \multicolumn{3}{|c|}{$\left(\chi^{2}=17.2 ; \mathrm{p}<0.01\right)$} & 8 \\
\hline \multicolumn{2}{|l|}{ Limit point of sale } & $\left(\chi^{2}=14.7 ; \mathrm{p}<0.01\right)$ & & & & & & & \\
\hline Definitely would support & 62 & 46 & 63 & 60 & 71 & 53 & 72 & 51 & 65 \\
\hline Possibly would support & 23 & 28 & 23 & 24 & 20 & 26 & 21 & 27 & 20 \\
\hline Would not support & 14 & \multirow{2}{*}{\multicolumn{4}{|c|}{$\left(\chi^{2}=8.4 ; p=0.08\right)$}} & \multicolumn{3}{|c|}{$\left(\chi^{2}=14.6 ; p<0.01\right)$} & 15 \\
\hline \multicolumn{2}{|l|}{ Fine those who sell to minors } & & & & & & & & \\
\hline Definitely would support & 67 & 57 & 74 & 72 & 67 & 64 & 71 & 61 & 67 \\
\hline Possibly would support & 20 & 25 & 13 & 19 & 21 & 29 & 20 & 18 & 16 \\
\hline \multirow[t]{2}{*}{ Would not support } & 13 & \multirow{2}{*}{\multicolumn{3}{|c|}{$\left(\chi^{2}=6.7\right.$; n.s. $)$}} & 12 & \multirow{2}{*}{\multicolumn{3}{|c|}{$\left(\chi^{2}=3.0 ;\right.$ n.s. $)$}} & 16 \\
\hline & & & & & & & & & \\
\hline $\begin{array}{l}\text { No vending machine sales } \\
\text { Definitely would support }\end{array}$ & 68 & 50 & 74 & 68 & 75 & 55 & 78 & 58 & 70 \\
\hline Possibly would support & 20 & 30 & 14 & 20 & 17 & 24 & 15 & 27 & 17 \\
\hline Would not support & 12 & 20 & 12 & 12 & 8 & 21 & 7 & 15 & 13 \\
\hline \multicolumn{2}{|l|}{ No sponsoring sport/cultural events } & \multicolumn{4}{|c|}{$\left(\chi^{2}=12.1 ; p<0.01\right)$} & \multicolumn{3}{|c|}{$\left(\chi^{2}=17.9 ; \mathrm{p}=0.01\right)$} & \\
\hline Definitely would support & 48 & & 59 & & 55 & 22 & 57 & 37 & 23 \\
\hline Possibly would support & 26 & 34 & 18 & 28 & 26 & 42 & 25 & 22 & 22 \\
\hline Would not support & 26 & 36 & 22 & 33 & 19 & 36 & 18 & 37 & 23 \\
\hline \multicolumn{2}{|l|}{ Prevention curricula in schools } & & & & & & & & \\
\hline Definitely would support & 77 & 69 & 84 & 75 & 80 & 70 & 80 & 73 & 82 \\
\hline Possibly would support & 18 & 21 & 14 & 21 & 16 & 27 & 18 & 16 & 13 \\
\hline Would not support & 5 & 9 & $\stackrel{2}{2} x^{2}=6$ & $\begin{array}{c}4 \\
3 ; \text { n.s. })\end{array}$ & 4 & 3 & $\stackrel{2}{2} \chi^{2}=5$ & $\begin{array}{c}11 \\
5 ; \text { n.s. })\end{array}$ & 5 \\
\hline
\end{tabular}
$+\chi^{2}$ statistic reflects the relationship between specialty and expressed support when effects of stratifying variables are control-

disappeared (results not shown). Group practitioners were no more likely than solo practitioners to support control measures when controlling for the specialty of respondents. Similarly, differences in attitudes expressed by practitioners with 1-14 years in practice and those with 15 or more years disappeared when the specialty of respondents was taken into account.

Intention to support control policies was associated with self-report of the frequency of smoking prevention counselling in a respondent's practice (table 3). Practitioners who reported "more frequent" counselling of 13to 15-year-old patients not to smoke (ie, respondents reported "always" or "frequent" counselling) were more likely than respondents who reported "less frequent" counselling (ie, "occasional" or "never" counselling of this age group). For example, $72 \%$ of those who more frequently counsel expressed definite support of limiting point of sale of tobacco products compared to $52 \%$ of respondents who reported less frequent counselling. Similarly, $78 \%$ of those who reported more frequent counselling expressed definite support for prohibiting sale of tobacco through vending machines, whereas such support was expressed by only $55 \%$ of practitioners who counsel less frequently. Sizable differences between groups were also noted regarding measures to prohibit tobacco companies from sponsoring sport/ cultural events, to increase tobacco sales tax; to require tax revenues to be spent on tobacco use prevention programmes, and to ban advertising of tobacco in public places. These differences in attitudes according to the reported counselling practices of respondents were not substantially altered by controlling for the specialty, practice arrangement, or years in practice of respondents.

Unfortunately, relatively few respondents matched the generalised support they expressed for tobacco control policy with personal initiatives to promote such policies (see table 4). Approximately one in five of respondents indicated that they avoided the products and investments of tobacco companies. A similar proportion reported that they obtained information or attended programmes on how to counsel patients to avoid tobacco use. The proportions of physicians and dentists who made monetary contributions to prevention programmes, addressed school children on tobacco and health, contacted public officials, wrote editorials, or signed tobacco control petitions were even lower. Four of the seven comparisons between specialists revealed significantly more activity among physicians than dentists.

\section{Discussion}

Counselling young adults not to become smokers and instituting policies to limit their access to tobacco products are critical elements of a comprehensive strategy to achieve a 
Table 3 Percentage of respondents expressing intent to support tobacco control policies, by self-reported frequency of tobacco prevention counselling of adolescents by respondents

\begin{tabular}{|c|c|c|}
\hline \multirow[b]{2}{*}{ Proposed control measure } & \multicolumn{2}{|c|}{ Frequency of counselling } \\
\hline & $\begin{array}{c}\text { Always/frequently } \\
\quad(n=182)\end{array}$ & $\begin{array}{c}\text { Occasionally/never } \\
(n=219)\end{array}$ \\
\hline \multicolumn{3}{|l|}{ Higher sales tax } \\
\hline Definitely would support & 81 & 73 \\
\hline Probably would support & 15 & 16 \\
\hline Would not support & 4 & 10 \\
\hline Allocate tax for prevention & \multicolumn{2}{|c|}{$\left(\chi^{2}=6.4 ; \mathrm{p}=0.04\right) \dagger$} \\
\hline Definitely would support & 67 & 48 \\
\hline Probably would support & 24 & 40 \\
\hline Would not support & 9 & 12 \\
\hline Ban advertising from public areas & \multicolumn{2}{|c|}{$\left(\chi^{2}=14.6 ; \mathrm{p}<0.01\right)$} \\
\hline Definitely would support & 85 & 66 \\
\hline Probably would support & 9 & 21 \\
\hline Would not support & 6 & 13 \\
\hline Limit point of sale & \multicolumn{2}{|c|}{$\left(\chi^{2}=19.3 ; p<0.01\right)$} \\
\hline Definitely would support & 72 & 52 \\
\hline Probably would support & 17 & 29 \\
\hline Would not support & 11 & 52 \\
\hline Fine those who sell to minors & \multicolumn{2}{|c|}{$\left(\chi^{2}=17.9 ; \mathrm{p}<0.01\right)$} \\
\hline Definitely would support & 71 & 61 \\
\hline Probably would support & 17 & 24 \\
\hline Would not support & 12 & 15 \\
\hline$\left(\chi^{2}=4.9 ; \mathrm{p}=0.09\right)$ & \multicolumn{2}{|c|}{$\left(\chi^{2}=4.9 ; \mathrm{p}=0.09\right)$} \\
\hline Definitely would support & 78 & 55 \\
\hline Probably would support & 14 & 26 \\
\hline Would not support & 8 & 18 \\
\hline & \multicolumn{2}{|c|}{$\left(\chi^{2}=24.7 ; \mathrm{p}<0.01\right)$} \\
\hline $\begin{array}{l}\text { No sponsoring sport/cultural events } \\
\text { Definitely would support }\end{array}$ & 57 & 37 \\
\hline Probably would support & 24 & 29 \\
\hline Would not support & 19 & 34 \\
\hline & $\left(\chi^{2}=17\right.$ & $<0.01)$ \\
\hline \multicolumn{3}{|l|}{ Prevention curricula in schools } \\
\hline Definitely would support & 81 & 72 \\
\hline Probably would support & 14 & 22 \\
\hline \multirow[t]{2}{*}{ Would not support } & 4 & 6 \\
\hline & \multicolumn{2}{|c|}{$\left(\chi^{2}=4.6 ; p=0.10\right)$} \\
\hline
\end{tabular}

$+\chi^{2}$ statistic reflects the association reported in $2 \times 3$ tables between counselling activity and expressed support.

Table 4 Self-reported activities over previous 12 months to control tobacco, by specialty

\begin{tabular}{|c|c|c|c|}
\hline Activity & $\begin{array}{l}\text { Physicians (\%) } \\
\quad(n=105)\end{array}$ & $\begin{array}{l}\text { Dentists }(\%) \\
\quad(n=166)\end{array}$ & $\begin{array}{l}\text { Total }(\%) \\
(n=443)\end{array}$ \\
\hline $\begin{array}{l}\text { Made monetary contribution to } \\
\text { prevention programmes }\end{array}$ & \multicolumn{2}{|c|}{$(\mathrm{z}=2.4 ; \mathrm{p}=0.02) \dagger$} & 6 \\
\hline $\begin{array}{l}\text { Avoided products and investments of } \\
\text { tobacco companies }\end{array}$ & \multicolumn{2}{|c|}{$\stackrel{25}{(z}=2.1 ; p=0.04)$} & 22 \\
\hline $\begin{array}{l}\text { Obtained information or attended } \\
\text { programmes on how to counsel } \\
\text { patients to avoid tobacco use }\end{array}$ & \multicolumn{2}{|c|}{$\stackrel{27}{(z}=3.6 ; p<0.01)$} & 21 \\
\hline $\begin{array}{l}\text { Addressed school children on tobacco } \\
\text { and health }\end{array}$ & \multicolumn{2}{|c|}{$(z=2.6 ; p=0.01)$} & 12 \\
\hline $\begin{array}{l}\text { Contacted legislators or other public } \\
\text { officials to express support for tobacco } \\
\text { control efforts }\end{array}$ & \multicolumn{2}{|c|}{${ }^{2}(\mathrm{z}=1.4 ; \text { n.s. })^{0}$} & 1 \\
\hline $\begin{array}{l}\text { Wrote editorials or commentaries for } \\
\text { local newspapers }\end{array}$ & \multicolumn{2}{|c|}{$(\mathrm{z}=0.5$; n.s. $)$} & 1 \\
\hline $\begin{array}{l}\text { Signed petitions on tobacco control } \\
\text { initiatives }\end{array}$ & \multicolumn{2}{|c|}{$4(z=0.9 ; \text { n.s. })^{2}$} & 3 \\
\hline
\end{tabular}

$\dagger \mathrm{z}$ scores reflect significance of difference in proportions between specialty groups.

smoke-free society. ${ }^{15}$ Physicians and dentists who care for adolescent patients are in unique positions to advance these objectives.

This analysis documented considerable support among primary health care providers for enacting further tobacco control policies. The findings suggest, however, that attitudes toward such measures varied to a great extent according to the backgrounds and practices of respondents. Support for control measures was pronounced among physicians while somewhat tempered among dentists. Practitioners who had never smoked and those who reported that they more frequently counsel adolescent patients not to smoke expressed greater support for control measures than those who had ever smoked and those who did tobacco prevention counselling less frequently.

Despite the good response to the survey, the generalisability of results could not be evaluated. If present, selection bias probably overstated the support and activity of practitioners to control access to tobacco. Additional work to corroborate these results is encouraged.

Initiatives to control access to tobacco should capitalise on potential support that exists among health practitioners. Strategies to reduce the risk of tobacco addiction in young people would be enhanced by encouraging health care providers to be effective change agents in public, as well as clinical, settings. Fortunately, a large menu of options for advancing collective health objectives can be readily identified to suit individual interests and abilities. It is unlikely at the present time, however, that more than a minority of practitioners appreciate, and act upon, that role of public health activist. Principles that ground clinical practice within the broader public health debate need further elaboration within curricula of schools of medicine and dental medicine. ${ }^{18}$ Appropriate role models must to be identified and methods for building requisite skills in policy analysis, public discourse, community mobilisation, and the like, need additional refinement.

1 US Public Health Service. Healthy people 2000: National health promotion and disease prevention objectives. (DHHS Publication No (PHS) 91-50212.)

2 Selected tobacco use behaviors and dietary patterns among high school students - United States, 1991. MMWR $1992 ; 41: 417-21$.

3 Fischer PM, Schwartz MP, Richards JW, et al. Brand logo recognition by children aged 3 to 6 years. $\mathscr{F} A M A 1991$ 226: 3145-8.

4 Di Franza JR, Richards JW, Paulman PM, et al. RJR Nabisco's cartoon camel promotes camel cigarettes to children. fAMA 1991; 266: 3149-53.

5 Basil MD, Schooler C, Altman DG, et al. How cigarettes are advertised in magazines: Special messages for special markets. Health Commun 1991; 3: 75-91

6 Pierce JP, Gilpin E, Burns DM, et al. Does tobacco advertising target young people to start smoking? $\mathcal{F} A M A$ $1991 ; 266$ : 3154-8.

7 US Centers for Disease Control. State laws restricting minor's access to tobacco. MMWR 1990; 40: 754-7

8 Cummings KM, Pechacek T, Shopland D. The illegal sale of cigarettes to US minors: estimates by state. $A m \mathcal{F}$ Public Health 1994; 84:300-2.

9 Altman D, Carol J, Chalkley C, et al. Report of the Tobacco Policy Research Study Group on access to tobacco
Altman D, Carol J, Chalkley C, et al. Report of the Tobacco products in the United States. Tobacco Control 1992; 1(Suppl): 45-5

10 DiFranza JR, Brown LJ. The Tobacco Institute's "It's the Law" campaign: Has it halted illegal sales of tobacco to children? Am $\mathcal{F}$ Public Health 1992; 82: 1271-3.

11 Diel HS, The physician and cigarette smoking. The New Physician 1970; 17: 231-4.

12 Seffrome JR, Stauffer DJ. Patient education on cigarette smoking: the dentist's role. $\mathcal{F} A D A$ 1976; 92: 7514

13 Epps RP, Manley MW. A physician's guide to preventing tobacco use during childhood and adolescence. Pediatrics $1991 ; 88: 140-4$

14 Elster AB, Kuznets NJ, eds. AMA guidelines for adolescant preventive services (GAPS): recommendations and rationale. Baltimore, Maryland: Williams \& Wilkens, 1994

15 Freidson, E. Profession of Medicine, New York: Harper \& Row, 1970.

16 US Centers for Disease Control. State tobacco prevention and control activities: Results of the 1989-1990 Association of State and Territorial Health Officials (ASTHO) survey final report. MMWR 1991: 40 (No RR-11)

17 SYSTAT: Statistics, Version 5.2 Edition. Evanston, IL: SYSTAT, Inc, 1992

18 Greenlick MR, Educating physicians for population-based clinical practice. $\mathcal{F} A M A$ 1992; $267: 1645-8$. 